\title{
Immunisation against hepatitis B in Taiwan
}

\author{
I D Gust
}

\begin{abstract}
Hepatitis $B$ is hyperendemic in Taiwan; more than $15 \%$ of adults are chronic carriers of the virus and longterm sequelae (chronic active hepatitis, cirrhosis, and hepatocellular carcinoma) are common. A national immunisation programme was implemented in 1984 to tackle the problem. This entailed immunisation of newborn children, followed by susceptible school children and young adults. The programme, which has been in place for a decade, has resulted in a pronounced reduction in the prevalence of $\mathrm{HBsAg}$ among young children and seems to have led to a reduction in horizontal transmission among older children.

(Gut 1996; 38 (suppl 2): S67-S68)
\end{abstract}

Keywords: hepatitis B, immunisation, Taiwan.

\section{Background to the programme}

Taiwan was the site of many of the seminal studies on transmission of hepatitis $B$ virus (HBV) infection - especially a series of studies that defined the importance of carrier mothers in maintaining the chain of hepatitis B infection and showed that perinatal transmission could be reduced by passive or active immunisation, or both. ${ }^{12}$ Early epidemiological studies in Taiwan showed that the hepatitis B surface antigen (HBsAg) carrier rate in the general population was between 15 and $20 \%$, that a high proportion of carrier mothers were hepatitis $\mathrm{B}$ e antigen ( $\mathrm{HBeAg}$ ) positive, and that perinatal transmission was probably responsible for 40 to $50 \%$ of the carrier pool. ${ }^{34}$ In addition, chronic active hepatitis, cirrhosis, and hepatocellular carcinoma were common in the adult population and about three quarters of people with these diseases were chronically infected with HBV. ${ }^{5}$

\section{Hepatitis B control programmes}

A government funded national hepatitis B control programme was started in $1982,{ }^{5}$ initially focusing on public education and research. It was coordinated by a cabinet level committee (the National Steering Committee), whose remit was to establish policy, assure inter-agency cooperation, allocate resources, and monitor the progress of the programme. A second group the Hepatitis Control Committee, comprising health professionals - provided input into aspects of implementation of the programme.

CSL Limited, Parkville, Victoria, Australia I D Gust

Correspondence to Dr I D Gust, CSL Limited, 45 Poplar Road, Parkville, Melbourne, Victoria 3052, Australia.

\section{Shape of the programme}

Because of the high cost of hepatitis B vaccines in the early $1980 \mathrm{~s}$, the programme initially focused on those areas in which immunisation was expected to provide the greatest benefit. From July 1984, all mothers were tested for HBsAg and HBeAg and babies born to HBsAg positive mothers were offered hepatitis $B$ vaccine. In addition, children born to $\mathrm{HBeAg}$ positive mothers received a dose of hepatitis $B$ immunoglobulin ( $\mathrm{HBIg}$ ), within 24 hours of birth. The vaccine schedule chosen was based on data that had been generated locally and entailed administration of four doses of hepatitis B vaccine ( $5 \mu \mathrm{g}$ dose) within five days of birth and at 1,2, and 12 months of age. Over the next few years, the programme was expanded to cover eventually all Taiwanese citizens at risk of infection (Table I). In July 1986, the selective immunisation policy was expanded to include all newborn babies, irrespective of the mother's serological status. (In addition, HBIg continued to be provided to babies born to carrier mothers). In 1987, preschool children and uninfected health care personnel were added; in 1988, elementary school children; 1989, high school children; 1991, college students and adults.

\section{Education}

A year before the immunisation programme started, an education booklet describing the importance of hepatitis B in Taiwan and the government's strategies for its prevention was produced and widely circulated to the health care community. This material was supplemented by training courses and films.

An intensive public education programme was established, involving television, radio, and the print media, which specifically targeted women of childbearing age and provided simple, easily recognised messages. Opportunities were taken to provide information as part of some other process (for example, handbooks for newly married couples, delivery of railway schedules, etc) and extensive use was made of posters and television advertisements. Seminars and lectures were conducted for women's groups and a special telephone hotline established to answer questions from the public. Recognising the importance of reducing transmission in early life, particular emphasis was placed on the education of people in charge of day care centres and kindergartens and these people were used as a link to the children's parents. Elementary

TABLE I Hepatitis B immunisation programme in Taiwan

\begin{tabular}{ll}
\hline 1984 & Babies born to carrier mothers \\
1986 & Routine immunisation of newborns \\
This programme has been supplemented by campaigns to \\
immunise susceptible groups \\
1987 & Preschool children, medical personnel \\
1988 & Uninfected elementary school children \\
1989 & Uninfected high school children \\
1991 & Uninfected college students and adults \\
\hline
\end{tabular}


TABLE II Coverage of HBIg and hepatitis $B(H B)$ vaccine

\begin{tabular}{lllll}
\hline & $H B I g(\%)$ & $H B 1(\%)$ & $H B 2(\%)$ & $H B 3(\%)$ \\
\hline 1985 & $81 \cdot 2$ & $92 \cdot 4$ & $90 \cdot 8$ & $88 \cdot 9$ \\
1986 & $82 \cdot 8$ & $92 \cdot 5$ & $90 \cdot 9$ & $89 \cdot 5$ \\
1987 & 67.5 & $92 \cdot 7$ & $89 \cdot 3$ & $87 \cdot 0$ \\
1988 & 65.4 & $95 \cdot 2$ & $92 \cdot 4$ & $89 \cdot 8$ \\
1989 & $65 \cdot 2$ & 93.1 & $91 \cdot 3$ & $89 \cdot 4$ \\
1990 & $63 \cdot 2$ & $97 \cdot 7$ & 94.9 & 88.4 \\
Total & $70 \cdot 4$ & 94.6 & 91.9 & 88.7 \\
\hline
\end{tabular}

school children were provided with attractive booklets featuring cartoon figures reminding parents of the importance of immunisation.

Pregnant women received a booklet of coupons, which could be redeemed for vaccine (and HBIg, if necessary). Each book had an identifying number, which was shown to and recorded by the doctor during labour and at each antenatal visit. After each injection, the coupon was forwarded to the Department of Health, where the details were used to manage the programme and measure compliance.

In recent years, the department introduced a bonus system, in which districts reaching certain immunisation targets were rewarded with bonuses and repeat poor performances were recognised and followed up.

\section{Outcome of the programme}

The impact of the national hepatitis $B$ immunisation programme has been carefully monitored at regular intervals. ${ }^{6-9}$ In reviewing the national experience over the six year period from July 1984 to June $1990,{ }^{9}$ it was found that $77 \cdot 8 \%$ of almost two million women who had become pregnant during the period had been screened for HBsAg, with the proportion screened being essentially constant throughout the period. Of those who were tested, $16.4 \%$ were found to be carriers of HBsAg and $45.6 \%$ of these were regarded as highly infectious on the basis of either an HBsAg titre of $\geqslant 1: 2560$ by RPHA or the presence of $\mathrm{HBeAg}$.

Among babies born to carrier mothers, $70.4 \%$ received a dose of $\mathrm{HBIg}$ shortly after birth. The proportion of infants receiving their first, second, third, and fourth doses of hepatitis $B$ vaccine were $94.6 \%, 91.9 \%, 88.7 \%$, and $76 \cdot 2 \%$, respectively, with little variation year on year (Table II).

While the coverage figures are most impressive, the key measure of the efficacy of the programme is its impact on the carrier rate among children. Cross sectional studies of sera collected from children born before and after the onset of the programme have shown a noticeable decline in the prevalence of HBsAg among children less than 5 years of age, a decline in the prevalence of HBsAg in babies born to highly infectious mothers from $90 \%$ in

TABLE III Prevalence of $\mathrm{HBs} A \mathrm{~g}$ before and after the programme

\begin{tabular}{cccl}
\hline Age $(y)$ & $1984(\%)$ & $1989(\%)$ & $p$ Value \\
\hline $1-2$ & 10.7 & 1.5 & $<0.0005$ \\
$3-4$ & 10.1 & $2 \cdot 2$ & $<0.0005$ \\
$5-6$ & 10.6 & 3.9 & $<0.05$ \\
$9-10$ & 11.0 & $9 \cdot 8$ & NS \\
$11-12$ & $9 \cdot 1$ & 10.5 & NS \\
\hline
\end{tabular}

1984 to $15 \%$ in 1989 , and a significant reduction in hepatitis B infection among older (9-12 year old), but unimmunised, children, presumably as a result of declining rates of horizontal transmission (Table III). ${ }^{9} 10$

\section{Lessons from the programme}

While the results of the programme have been impressive, some $22 \%$ of pregnant women were not screened for HBsAg, probably because they remain unaware of the programme.

In 1989, the Department of Health commissioned a study that sought to identify factors associated with failure of children to receive all four doses of vaccine. The study used a random sample of more than 2500 women, in both rural and urban areas. The study suggested that parents' knowledge of, and attitudes to, vaccines were of major importance and that children whose fathers were better educated and whose mothers did not work were more likely to have received a full course of injections. The time of the year at which children were born seemed to have an effect, those requiring immunisation in midwinter having lower rates of completion.

The success of the programme seems to be due to two factors: (a) support from the government, both in establishing the programme as a priority and mobilising the resources needed to implement it and in its careful design and implementation; (b) sufficient time allowed from planning, consultation with and education of opinion leaders, generation of educational material, and involving the private and public sectors.

Despite its success to date, much attention is being paid to improving the programme by education specifically targeted at less privileged groups, making access to immunisation more convenient, shortening the waiting times at public clinics, and improving data handling, so that parents of children who have failed to receive a dose of vaccine will receive regular reminders.

1 Beasley RP, Hwang L-Y, Lin CC, et al. Hepatitis B immune globulin (HBIG) efficacy in the interruption of perinatal transmission of hepatitis B carrier state. Lancet 1981; ii: 388-93.

2 Stevens CE, Taylor PE, Tong MJ, et al. Prevention of perinatal hepatitis $B$ virus infection with hepatitis $B$ immune globulin and hepatitis $B$ vaccine. In : Zuckerman AI and liver disease. New York: Alan $\mathrm{RJ}$, ed. 1988: 982-8.

3 Stevens CE, Beasley RP, Tsui J, et al. Vertical transmission of hepatitis B antigen in Taiwan. N Engl F Med 1975; 292: 774-7.

4 Chen DS, Sung JL, Lai MY. A seroepidemiological study of hepatitis B infection in Taiwan. 7 Formosan Med Assoc 1978; 77: 908-18.

5 Chen DS, Sung JL. Hepatitis B virus infection and chronic iver diseases in Taiwan. Acta Hepatogastroenterol 1978; 25: 423-30.

6 Chen DS, Hsu NHM, Sung JL, et al. A mass vaccination programme in Taiwan against hepatitis B virus infection in infants of hepatitis B surface antigen-carrier mothers. fAMA 1987; 257: 2597-603

$7 \mathrm{Hsu}$ HM, Chen DS, Chuang CH, et al. Efficacy of a mass hepatitis $B$ vaccination programme in Taiwan: studies of 464 infants of mothers. FAMA 1988; 260: 2231-5.

8 Tsen Y-J, Chang M-H, Hsu HY, et al. Seroprevalence of hepatitis B virus infection in children in Taipei, 1989: five years after a mass hepatitis

9 Wong WCW, Tsang KK. A mass hepatitis B vaccination programme in Taiwan: its preparation, results and reasons programme in Taiwan: its preparation, results and reasons

$10 \mathrm{Hsu} \mathrm{H}-\mathrm{Y}$, Chang M-H, Chen DS, et al $1994 ; 12$ : $229-34$ miology of hepatitis B virus infection in children in Taipei, miology of hepatitis $B$ virus infection in children in Taipei, programme in Taiwan. $\mathcal{F}$ Med Virol 1986; 18: 301-7. 